\title{
MORPHINE HYPERSENSITIVITY IN KYPHOSCOLIOSIS
}

\author{
BY \\ RAYMOND DALEY \\ From St. Thomas's Hospital \\ Received November 8, 1944
}

It has been recognized since the time of Hippocrates that patients suffering from " hump back" die young. The first descriptions of early death in persons suffering from severe kyphoscoliosis did not incriminate the cardiovascular system, and it was not until the end of the last century that continental observers described heart failure as being the most frequent cause. In 1930, Coombs made one of the first contributions to the English literature in a paper entitled, " Fatal cardiac failure in persons with angular deformity of the chest." More recently, in America, Chapman, Dill, and Graybiel (1939) have investigated twelve such cases, and in a review of others reported, showed that the average age at death was only thirty years. The purpose of this communication is to describe three patients whose deaths while in cardiac failure are believed to have been precipitated by the administration of morphia.

\section{CASE Notes}

Case 1. Male, aged 36; a hunchback as long as he could remember. He attended a school for physical defectives, but never aless played cricket and football. After leaving school, he led a comparatively normal life as a costermonger until the age of 30 , when he was admitted to hospital complaining of increasing dyspnœa on exertion, and of hæmoptysis.

On examination, a gross mid-dorsal kyphoscoliosis to the right. Pulse 86, regular. Slightly cyanosed. Neck veins engorged to within one inch of the angle of the jaw. Fine crepitations at both bases. Moderate œdema of both ankles. Liver palpable, but not tender. Heart enlarged to the right and left. Heart sounds normal. No murmurs. Blood pressure, 180/130. Retinæ normal.

He was treated with Guy's pill and mercurial diuretics, and discharged three weeks later, having recovered from his failure. He felt well, and was working for two-and-a-half years before he was again admitted in failure. He was then orthopnœic, with a regular pulse rate of 90, and a blood pressure of 170/140. An X-ray photograph of his chest showed marked enlargement of both ventricles, and pulmonary congestion. An electrocardiogram was within normal limits. On the evening of his admission, he was given oxygen by B.L.B. mask, and morphia, 1/4 of a grain, for the first time, The respirations became increasingly shallow, and death occurred in one hour.

Post-mortem examination. Heart weight, $606 \mathrm{~g}$. Both ventricular walls markedly thickened. Moderate atheroma of the pulmonary arteries. Coronary arteries and aorta normal. Lungs: left more emphysematous than right; both congested.

Case 2. Male, aged 36. He complained of increasing dyspnœa for two months. His back had begun to be " humped" at 24 years of age. This had gradually increased to reach its present severity six years ago.

On examination, orthopnœic, with cyanosis. Ventricular rate 88 , auricular fibrillation. Neck veins engorged; marked œdema of legs and sacrum; crepitations at both bases. Heart enlarged one inch to right of sternum. Pulmonary second abnormally loud. No murmurs. Blood pressure 110/70. Retinæ normal. A very marked mid-dorsal kyphoscoliosis to the 
right. A cardiogram confirmed auricular fibrillation, and showed right ventricular preponderence.

He was given 2 c.c. of mersalyl intravenously, and oxygen by B.L.B. mask. On the night of admission, morphia, $1 / 4$ of a grain, was given. One hour later the respirations became very shallow, and he died in five minutes.

Post-mortem examination. Heart weight, $490 \mathrm{~g}$. Right ventricle greatly hypertrophied. Coronary arteries normal. Pulmonary artery atheromatous, with a circumference twice that of the aorta. Aorta normal. Lungs very œdematous, with diffuse emphysema.

Case 3. (Communicated by Dr. Macoun.) Male, aged 43. He complained of dyspnœa on exertion for eighteen months. He had a severe high right thoracic kyphoscoliosis which had not prevented him pursuing his occupation as gardener until shortly before admission, when the dyspnœa became so severe that he could not continue. He then had no evidence of congestive failure. Pulse rate 90, with ventricular extrasystoles. Blood pressure 140/100. Apex beat displaced four-and-a-half inches from the midline in the fourth intercostal space. Cardiac dullness to the right of the sternum. Heart sounds normal, and no murmurs. $\mathrm{He}$ was treated by rest in bed, mercurial diuretics, and theominal, and responded sufficiently well for him to be discharged to light work in four weeks. Four weeks later, he was precipitated into failure by a mild bronchitic attack. He was then moderately cyanosed. Pulse rate, 100, regular. Respirations 26. Temperature normal. Hepatic enlargement, and œdema of the ankles. Rhonchi heard over both lungs. Treatment again consisted of bed, rest, and mercurial diuretics, with some improvement. He was having restless nights, but in view of the experience of the first two cases, it was decided to give a small dose of morphia, 1/12 of a grain, before resorting to more usual dosage. The respirations became greatly depressed, and he died in one-and-a-quarter hours.

Post-mortem examination. Heart weight, $460 \mathrm{~g}$. Right ventricular wall hypertrophied and dilated. Atheroma at origin of left anterior descending coronary artery. Circumference of pulmonary artery at upper level of valves, $8 \cdot 2 \mathrm{~cm}$. Circumference of aorta, $6 \cdot 5 \mathrm{~cm}$. No atheroma of pulmonary artery and only one small patch in aorta. Both lungs very small, with emphysema at borders. Bronchi congested and œdematous, typical of acute bronchitis.

\section{Discussion}

None of these patients had ever had morphia administered before the night of their death. The altered respirations and the times of death indicate that morphia probably played a part. Morphia has to be used with care in cyanosis, but it is common experience that, despite cyanosis, many cardiac patients react very favourably to its use. It is therefore reasonable to assume that severe kyphoscoliosis and the associated intrathoracic abnormalities have a bearing on this idiosyncrasy.

Trendelenberg (1926), remarking on morphine in kyphoscoliosis, stated: "Whereas, when the usual therapeutic amounts are given to people with unrestrained breathing, the crippling is usually shown only in a dulling of the breathing, and moderate diminution of breathing volume; in people with restrained breathing (dyspnca following foreign body in the air passages, abnormal thoracic structure, etc.) even the usual therapeutic doses can so severely deteriorate the pulmonary ventilation through central effect on the breathing centre that life is threatened. In such cases, therefore, morphine should be used with the greatest care."

Chapman, Dill, and Graybiel describe the case of a girl, aged 29, with a severe high right kyphoscoliosis, who was given $1 / 3$ of a grain of pantopon before an operation. Within a few minutes she became so cyanosed and dyspnœic that she had to be placed in an oxygen tent, and her condition remained critical for eight days.

Schroeder described an eclamptic patient whose respirations were depressed to between 2 and 3 a minute after the administration of $1 / 6$ of a grain of morphia.

Severe kyphoscoliotic patients, even in the absence of cardiac failure, have greatly reduced vital capacities. In six such adult patients I have obtained values varying from 850 to 1850 c.c. 
In the case of Chapman, Dill, and Graybiel, mentioned above, it was only 560 c.c. Once cardiac failure has supervened, the values will certainly be less. Any event that still further reduces pulmonary function, such as pulmonary infections, or the use of respiratory depresants, is quite sufficient to cause death. Cases 1 and 2, uncomplicated by infection, died after $1 / 4$ of a grain of morphia. Case 3, complicated by infection, could not survive $1 / 12$ of a grain. It is therefore suggested that morphia has no place in the treatment of heart failure consequent upon kyphoscoliosis.

\section{SUMMARY}

Three cases are described of severe kyphoscoliosis and cardiac failure who died after the administration of morphia in small dosage. Reference is made to two cases, reported previously by others, who were precipitated into crises by respiratory depresants.

My thanks are due to Sir Maurice Cassidy for permission to publish Cases 1 and 2, and to Dr. Stephen Macoun for the details of Case 3.

\section{REFERENCES}

Chapman, E. M., Dill, D. B., and Graybiel, A. (1939). $\quad$ Medicine, 18, 167.

Coombs, C. F. (1930). Brit. J. Surg., 18, 326.

Schroeder, Carl (1926). Z Zbl. Gynäk., 1621.

Trendelenberg, P. (1926). Grundlagen der allgemeinen und speziellen Arzneiverordnung, Leipzig. 